\title{
Evaluation of Knowledge Management Application on Bank Central Asia (BCA)
}

\author{
Ardiansyah Haryanto \\ Doctoral Program, Human Resource Management, State University of Jakarta \\ Jl. Rawamangun Muka, RT.11/RW.14, Rawamangun, Jakarta Timur, 13220 \\ E-mail: Ardits009@gmail.com
}

Hady Efendy (Corresponding Author)

Education Practice and Academic Consultant

E-mail: efendy_hady@yahoo.co.id

Received: Aug. 25, 2017 Accepted: Sep. 14, 2017 Online published: Sep. 22, 2017

doi:10.5296/ijhrs.v7i4.11743 URL: https://doi.org/10.5296/ijhrs.v7i4.11743

\begin{abstract}
The increasingly global business competition has an impact on the increasing demands of competitiveness among companies in Indonesia in order to survive, the ability of decision making and solving a problem and effective managerial capability requires the company has strong intellectual capital and embrace open system to be able to respond more easily to the needs and needs of stakeholders in the company. Knowledge Management System (KMS) is a system created to facilitate the capture, storage, retrieval, transfer and reuse of knowledge. The purpose of making KMS is to create and build technology that can help users to reduce the tacit knowledge into explicit knowledge to be used in dealing with a problem with knowledge in accordance with the procedures of a company or organization in the action to handle the problem. Every company or organization has done the implementation of knowledge management system, not least in Bank Central Asia (BCA). BCA's strategy focuses on growth, credit quality and efficiency that enable BCA to achieve high-quality growth and enhance its role as a transactional Bank providing payment settlement services in support of achieving a strong Indonesian economy and national development goals. This research explains how far the application of knowledge management system conducted by BCA.
\end{abstract}

Keywords: Knowledge Management, tacit knowledge, explicit knowledge, open system 
management.

\section{Background}

Today's increasingly global business competition has an impact on the increasing demands of competitiveness among companies in Indonesia in order to survive moreover to be more advanced, the ability to make decisions and solve problems and effective managerial capabilities requires companies to have intellectual capital strong and embrace open system. Companies or organizations that embrace open systems can more easily respond to the wants and needs of stakeholders in the company (stakeholders).

According to Katz and Kahn (1978) in the book "a guide book knowledge management effectively innovate successfully" open system has characteristics such as the ability of the organization to make adjustments based on information, feedback and feedback from the environment, it consists of cyclic events, tend to grow and have various means (equifinality) to achieve the goal. The input are: human resources, information and knowledge. To support open system organizations need to implement systems that can identify, create, present, distribute, and adopt insights and experiences. Insights and experiences consisting of both tacit and explicit information and knowledge both contained in each individual and in the process in the organization can be recorded and channeled.

Efforts must be made by each company/organization in identifying, creating, presenting, distributing, and adopting existing insights and experiences for each individual. It is necessary for facilities or activities that can facilitate every individual or member of an organization to be able to convey their idea or idea. Delphi Group's research results show that knowledge in the organization, $42 \%$ is stored and structured in the mind or brain of employees, $26 \%$ in paper documents, $20 \%$ in electronic documents and $12 \%$ in the form of electronic knowledge base (Bambang Setiarso, 2009).

This condition reflects that the condition of knowledge management within a company has not been conceptualized well so that it has not mutually give positive benefits among its members, for that information and knowledge both tacit and explicit that is stored neatly in each mind and minding each individual In the organization needs to get good advice so that it can be stored and well documented in a system at a company or organization. What is expected is not only to add to the information or knowledge of each individual, but also to stimulate the birth of new ideas or new innovations to create things that can be useful for the progress of the company or organization.

The importance of the learning organization has long been the concern of organizational experts, especially since the publication of Peter Senge's book "The Fifth Discipline" in 1990. In addition organizations of both business and non-business organizations have also tried to develop the concept in an effort to make competitive organizations. Companies should adhere to learning organization or learning organization so that its employees can always do continuous learning for the creation of new and added value-added products and services, the implication of the learning organization is the need to apply Knowledge Management (KM) system to get many ideas and information from various parties is then managed to become a 
knowledge that produces innovative products or services. In the context of open systems, the management of knowledge management (KM) needs to refer to the needs and desires of the stakeholders in the form of appropriate outputs.

Based on these conditions each company or organization seeks to harmonize with the development of environment, technology and information and knowledge needs. The basic things behind the formation of knowledge management system is that every company really need information or knowledge that is tacit or explicit that is still stored neatly in each mind and thought every individual can be distributed and studied so that when one of the employees is no longer working then the thinking -the mind is still documented on the system knowledge management company or organization.

Today almost every company or organization has been implementing knowledge management system, not least in Bank Central Asia. The era of globalization today makes the transition of a company's assets not only tangible assets but also knowledge assets, information, ideas and ideas that exist in the minds of employees of a company or organization (intangible). The impact of the paradigm shift according to Bergerson (2003) is that knowledge becomes a valuable asset for any company or organization in the world.

According to wikipedia.org knowledge management (KM) is a phrase that describes a series of strategies, systems and techniques used by individuals, teams and corporations to manage knowledge. For many KM practitioners 'knowledge' is more likely to be interpreted as the 'insight', 'insights' or 'experience' subjective that a person acquires when practicing an information in reality. Knowledge is then generally standardized in the form of business processes, practices, regulations or other forms of documentation. In accordance with the nature of 'knowledge' is so subjective, validation of an 'individual knowledge' to 'collective knowledge' can only be achieved if the knowledge sharing process (exchange of ideas or information for each individual). Collected knowledge that is validated and documented is a source of strength in the corporate context.

Improvement of skills and individual skills due to the application of knowledge management according to Bergerson (2003) can be achieved if the organization is able to apply knowledge management based on the vision and mission of the company or organization. To that end all departments within the organization are expected to do KM either consciously or not. The problem is that when KM is managed unplanned, organized and fully integrated with general business strategies (such as HR, IT, RM, TQM, SM, production, etc.), inefficiency and inefficiency will arise on all fronts. When this condition is confronted with the height of world competition, then corporations that do not care much about KM will tend to be trained and left behind in the competition.

\section{Formulation of the Problem}

Based on the background review that has been described above, below the authors summarize the formulation of the background of the background of writing a semester test, the formulation of the problem includes:

1. How is the effect of applying knowledge management system in Bank Central Asia? 
2. How can the effect of implementing knowledge management system improve the quality of Bank Central Asia's performance?

Based on the background and problem formulation in this research, the purpose of this research is:

1. Analyze the influence of application of knowledge management system in Bank Central Asia.

2. Analyzing the influence of application of knowledge management system can improve quality performance of Bank Central Asia.

\section{Theoretical Review}

\subsection{Knowledge}

Knowledge is an intimacy with someone or something, which can include facts, information, descriptions, or skills gained through experience or education. It can refer to the theoretical or practical understanding of the subject. It can be implicit (as with practical skills or expertise) or explicit (as with the theoretical understanding of the subject), and can be more or less formal or systematic. In philosophy, science is called epistemology. The famous philosopher Plato defined knowledge as "true justified belief." Yet no single-agreed knowledge definition exists, and there are many theories to explain it. The following quote from Bertrand Russell's "Theory of Knowledge" illustrates the difficulty in defining knowledge. "The question of how knowledge should be defined may be the most important and difficult of the three that we have to deal with. It may seem surprising. At first glance it may be thought that knowledge can be defined as a belief that is in accordance with the facts The problem is that no one knows what belief Is, nobody knows what really is, and nobody knows what kind of agreement between them will make a true belief. Let's start with confidence".

The acquisition of knowledge involves complex cognitive processes: perception, communication, association and reasoning, while knowledge is also said to be related to the capacity of recognition in humans. Davenport and Prusak (1998) defines broad knowledge with knowledge as a mixture of experience, value, informal contextual, and an expert view that provides a framework for evaluating and integrating new experiences and information. Knowledge is owned and applied in the mind of the knowledge owner. In the company, knowledge is often related not only to documents or documents, but also to the organization's routines, processes, practices and ethics.

Knowledge is an institutional asset, which determines the amount of workforce, information, skills, and organizational structure required. The company's knowledge and experience is a sustainable resource that benefits competitiveness compared to its leading products and advanced technology Knowledge and experience is able to create, communicate and apply everything related to achieving business goals.

Drucker (1998) defines knowledge as information that changes something or someone, it happens when the information becomes the basis for action, or when that information enables a person or institution to take action beforehand. So knowledge can be interpreted as 
actionable information or actionable information or information that can be used as a basis for action, to make decisions and to pursue certain directions or strategies whose purpose is to achieve the company's vision.

\subsection{Knowledge Management}

Knowledge management (Girard, John P., 2015) is the process of creating, sharing, using and managing the knowledge and information of an organization. This refers to a multi-disciplinary approach to achieving organizational goals by making the best use of knowledge.

Knowledge management typically focuses on organizational goals such as performance improvement, competitive advantage, innovation, shared learning, integration, and continuous improvement of the organization. These efforts overlap with organizational learning and may be distinguished from that with a greater focus on knowledge management as a strategic asset and a focus on encouraging knowledge sharing. KM is an organizational learning enabler.

Knowledge management has a long history, including on-the-job discussions, formal internships, discussion forums, corporate libraries, professional training, and mentoring programs. The increasing use of computers in the second half of the 20th century, tech-specific adaptations such as knowledge base, expert systems, knowledge repositories, group decision support systems, intranets, and computers-supported cooperative work have been introduced to further enhance these efforts.

In the company, the initial collection of case studies recognizes the importance of knowledge management, strategy, process and measurement dimensions. Knowledge of essential learning includes people and cultural norms that influence their behavior are the most important resources for successful knowledge creation, dissemination, and application, cognitive, social, and organizational learning processes are essential for the success of knowledge management strategies, and measurement, benchmarking, and incentives are essential to accelerate the learning process and to encourage cultural change. In short, knowledge management programs can generate impressive benefits for individuals and organizations if they are purposeful, concrete, and action-oriented.

\subsection{Dimensions of Knowledge Management}

In knowledge management, there are dimensions of different frameworks to differentiate between different 'types' of knowledge. One of the proposed frameworks for categorizing knowledge dimensions distinguishes tacit knowledge and explicit knowledge. Tacit knowledge is an internalized knowledge that an individual may unconsciously realize, such as to accomplish certain tasks. At the opposite end of the spectrum, explicit knowledge represents the knowledge that the individual holds conscious in the mental focus, in a form that can easily be communicated to others. 


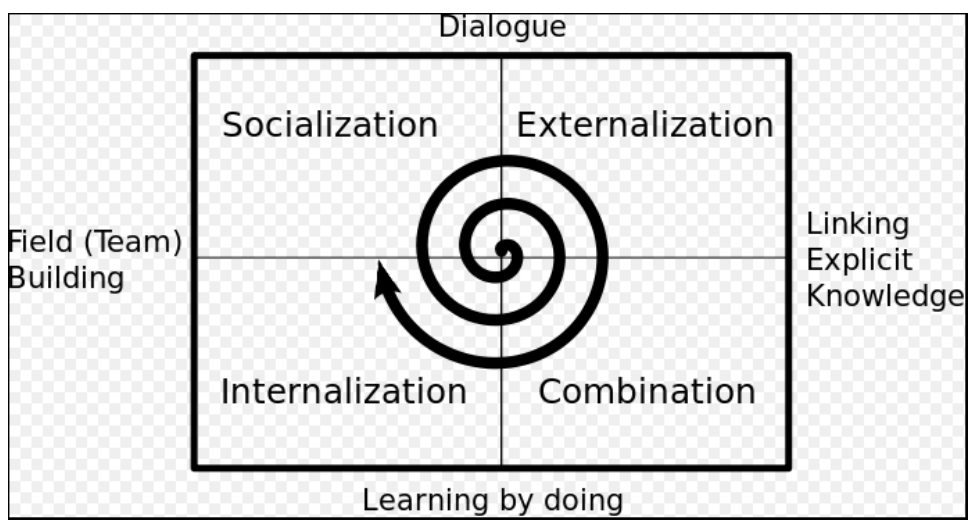

Figure 1. Dimension of Knowledge Management

Hayes and Walsham (2003) describe knowledge and knowledge management as two different perspectives. The content perspective suggests that knowledge is easily stored, as it may be codified, while the relational perspective recognizes the contextual and relational aspects of knowledge that can make knowledge difficult to share outside of the particular context in which it is developed. Initial research indicates that KM needs to convert internalized tacit knowledge into explicit knowledge for sharing, and the same effort should allow individuals to internalize and make meaningful personally codified knowledge derived from KM efforts.

Subsequent research shows that the difference between tacit knowledge and explicit knowledge is represented too simplistic and that the idea of explicit knowledge is contradictory. In particular, for the knowledge to be made explicit, it must be translated into information (i.e., symbols outside our heads).

A second proposed framework for categorizing knowledge dimensions distinguishes embedded knowledge of systems outside of the human individual (e.g., information systems can have embedded knowledge into the design) of the contained knowledge representing the learning abilities of the human nervous and endocrine systems. A third proposed framework distinguishes between the creation of an exploration of "new knowledge" (i.e., innovation) vs. transfer or exploitation of "established knowledge" within a group, organization, or community. Collaborative environments such as community practice or the use of social computing tools can be used for both knowledge creation and transfer.

\subsection{Knowledge Management System}

Knowledge Management System (KMS) is a system created to facilitate the capture, storage, retrieval, transfer and reuse of knowledge. In the knowledge management system there are two things that are needed in building this system that is tacit knowledge and explicit knowledge, both of which are used to make KMS become knowledge and can be used by others.

The purpose of making KMS is to create and build technology that can help users to reduce the tacit knowledge into explicit knowledge to be used in dealing with a problem with knowledge in accordance with the procedures of a company or organization in the action to 
handle the problem. The benefits of KMS implementation in an organization or company are:

- Can provide a faster response in handling problems that occur based on existing knowledge and even new knowledge in an organization.

- Creating new knowledge during the learning process that occurs in an organization where the knowledge represents a reasonable and valuable way for the organization.

- Store and process knowledge that is a valuable asset for the organization in performing an action in handling problems that occur during the business process takes place. The knowledge is stored in a good format for use at a time.

- Can distribute useful knowledge to members of organizations who need, wherever and whenever.

In Knowledge Management System (KMS) there are several supporting technologies that are used to support the implementation which consists of several categories, namely:

- Groupware-Technologies that facilitate collaboration and sharing of organizational information. One of the earliest successful products in this category is Lotus Notes. Notes tool provided for threaded discussions, document sharing, uniform email organization width, etc.

- Workflow - Workflow allows representation of processes related to the creation, use, and maintenance of organizational knowledge. For example, the process for creating and utilizing forms and documents.

- Content / Document Management - Systems that automate the process of creating web and / or document content. Roles such as editors, graphic designers, authors, and producers can be explicitly modeled along with the tasks in the process and validation criteria. Commercial vendors start either to support documents (e.g., Documentum) or to support web content (e.g., Interwoven) but as the Internet grows these functions are merged and vendors now perform both functions.

- Web Portal sites of companies that collect information throughout the organization or for groups such as project teams.

- ELearning-Allows organizations to create customized training and educational software. This may include lesson plans, progress monitoring and online classes.

- Scheduling and planning-Automate schedule creation and maintenance, e.g., Microsoft Outlook. Aspects of planning can integrate with project management tools such as Microsoft Project.

- Telepresence-Allows individuals to have virtual "face-to-face" meetings without gathering in one location. Videoconferencing is the most obvious example.

\subsection{Make (Most Admired Knowledge Enterprise)}

The history of most admired knowledge enterprise is built to improve company performance through the creation, development and application of knowledge into value for the company or organization. Most admired knowledge enterprise itself was born in 1998 and is one method to measure the maturity and commitment of knowledge management within a company or organization. Most admired knowledge enterprises themselves can be used as benchmarking or a method for companies or organizations to learn about best practices from 
knowledge-based organizations.

In the most admired knowledge enterprise must have 8 criteria that exist in the knowledge management in a company, to the eight criteria are:

Establish a culture of organizational knowledge (Organization Value).

1. Developing knowledge workers through senior leadership (Organization Learning).

2. Develop and realize products / services / knowledge-based solutions (Innovation).

3. Maximize the value of the company's intellectual capital (Intellectual Capital Management).

4. Creating and maintaining a wide range of knowledge (Customer / Employer Knowledge).

5. Creating and maintaining a corporate sustainable learning culture (Knowledge Sharing and Collaboration).

6. Managing the knowledge of customers / stakeholders to create value and intellectual capital of the company (Organization Culture).

7. Managing corporate knowledge to increase the value of stake or stakeholder stakeholders in the company (Leadership).

\subsection{Learning Organization}

The learning organization is a set of human beings who have purpose which is coordinated deliberately and "expert" in organizational learning. Marquardt (1996: 26) defines learning organization as an institution that learns powerfully and collectively, continually transforming itself to better manage and use knowledge for corporate success, empowering people within and outside the organization to learn how to work and utilize technology to maximize and production. Organizational learning (PO) is commonly known as organization learning which requires some experts in general can be equated with learning organization. Viewed from the semantic, PO is an activity of learning that is organizational. In other words PO emphasizes the learning process and related activities. Both PO and OP both are related to continuous learning that involves the process of information acquisition, interpretation of data and knowledge development.

In various literatures, the term or semantic learning organization is often used interchangeably with knowledge management (KM). Learning organizations rely on the cognitive processes of individuals in an organization where the learning organization emphasizes on things that are relatively similar to knowledge management i.e. learning and innovation.

According to Kezar (2005) learning organizations emphasize more on external threats as learning reasons need to be done, whereas organizational learning focuses more on internal issues to achieve targeted organizational performance. In addition, organizational learning is a condition that "demands" every individual in the organization does it. Organizational learning must be able to answer internal and external demands, where the learning organization emphasizes the learning process, while the $\mathrm{KM}$ is more on the outcome or outcome of a learning process. PO emphasizes as a process of detection and correction of errors, the PO members act as learning agents. 
In learning organization is expected ability of organization in learning both adaptively and generative through knowledge management, in order to survive, and grow flower. Through the creation and offering of innovative products, companies are able to compete and win.

\section{Discussion}

\subsection{The Knowledge Management Strategy of Bank BCA}

BCA's strategy focuses on growth, credit quality and efficiency that enable BCA to achieve high-quality growth and enhance its role as a transactional Bank providing payment settlement services in support of achieving a strong Indonesian economy and national development goals.

\subsubsection{Growth Focus}

As one of the leading bank of transaction and payment services in Indonesia, BCA is growing strongly and contributing significantly to national economic development. BCA has gradually expanded its role from transactional bank to a provider of financial solutions by offering more customer-oriented products. BCA also continues to strengthen its business in channeling credit and exploring new business opportunities to respond to customer needs and needs.

The result of this strategy is the solid credit growth, which in 2015 BCA's loan portfolio has grown $28.2 \%$ compared to the average growth of credit sector of the Indonesian franchise sector which grew only $24.1 \%$ on average. BCA is in a favorable position to continue to grow in the hands of economic conditions characterized by low levels of interest rates and growing customer demand.

\subsubsection{Quality is the Top Priority}

The way BCA improves quality is by deepening BCA's relationship with customers to understand and meet customers' needs so that customer satisfaction increases.

The results of this strategy include:

- Improving credit quality: by emphasizing quality lending based on credit criteria and rigorous monitoring and scrutiny, BCA has managed to improve the overall quality of the loan portfolio.

- Quality of products and services: BCA continues to improve the quality of its products and services to benefit customers. In 2010, BCA developed click-BCA and e-commerce technologies and continued to add other electronic security features such as smartphones.

\subsubsection{Efficiency is something to Do}

Growth quality must be balanced with the efficiency and optimization of the use of resources owned. Human resource development is a key element in efforts to improve efficiency. Some ways that BCA undertakes to improve its efficiency, among others:

- Optimizing human resources, infrastructure and logistics to support the growth of quality businesses. 
- Increase the competence of human resources at every level of the organization through a targeted training and education program.

- Investment in electronic distribution network infrastructure as a complement to branch physical network.

- Simplify operational and administrative procedures without abandoning prudential principles.

The high business competition needs to be addressed by increasing efficiency. Efforts to increase efficiency are carried out in a broad scope including cost efficiency and employee productivity optimization, as well as simplification of operational and administrative procedures with improved technological support. BCA conducts specialized and mass training programs for all employees throughout the work unit. Technology is used as an effective solution in all work units. Technology is utilized as an effective solution in educational programs such as e-learning and Video Based Training (VBT).

Conclusions on the results of BCA's strategy:

Supported by a healthy balance sheet, BCA benefits from conducive economic growth in Indonesia. The Board of Directors has demonstrated its competence and hard work in leading and directing the Bank as seen in the achievements of BCA, both in terms of operational and financial management. Discipline in implementing quality growth strategies has yielded positive results and puts the Bank in the right direction to capture business opportunities.

BCA managed to record satisfactory performance in 2015 BCA's credit has grown $28.2 \%$ compared to the average growth of credit sector of the sector of Indonesia which only grows on average $24.1 \%$. In line with the increase in profitability, BCA recorded a return on assets of $4.2 \%$ and a return on equity of $36.3 \%$ with a capital adequacy ratio of $15.3 \%$.

\subsection{Business Review Knowledge Management BCA}

BCA's main business is transactional exchange, with BCA gradually beginning to expand its role as a provider of financial solutions. Currently, transactional transactions through electronic networks continue to grow with the support of network expansion and innovation and development of banking transactions features. With extensive network coverage, branch banking remains the main link between BCA and its customers spread across the country.

As one of the leading transactional banks in Indonesia, BCA continues to meet customer demand for quality services by investing in infrastructure and improving its products and services, as well as developing the capability of its human resources. Technological advances have led to the expansion of the use of electronic banking services by customers in recent years, as reflected in the increasing frequency and value of banking transactions via the internet and mobile banking.

\subsubsection{Transactional Banking}

Supported by a comprehensive and integrated transactional banking infrastructure, BCA offers transaction convenience and creates a community where business and individual customers are connected through BCA's banking infrastructure. In 2015, BCA continues to 
innovate and develop transaction capacity to meet customer needs and improve customer convenience. To expand the service range, BCA added 27 branches and 848 ATMs as well as expanded merchant transaction activities through merchants with EDC-based as point of service. In addition, BCA developed a plication that facilitates access to internet banking services through smartphones.

Effort to increase customer loyalty is done through regular meetings between customers with BCA senior management and through various customer appreciation programs. Transactional banking activities through the electronic network continue to grow with the support of network expansion and innovation and development of transaction features in 2015. Use of internet banking and other electronic networks such as smartphones experienced a significant increase in both transaction and frequency.

BCA's stages continue to dominate as a key saving product that supports the strengthening of BCA's position as a transactional bank. BCA offers a diverse range of savings products for different segments of customers such as the gold stages for business segments, savings accounts for newly-learned children's savings segments, and priority accounts for customers with certain criteria. As well as other new products like BCA dollars, extra BCA, insurance, investments and deposits.

\subsubsection{Development of Transactional Brokerage Services}

The increasingly complex dynamics of the business world has spurred the need for customized banking services to accommodate the characteristics of different types of businesses. BCA responds to this opportunity by offering a demonstrable cash management for corporate and commercial customers with a broad value chain. BCA also serves the market segment in microfinance transactions by providing BCA Flazz Card services.

In 2015, BCA introduced a series of payment and collection services and liquidity monitoring to improve the management of business to business (B2B), business to customer (B2C) and customer to customer (C2C) transactions to support cash management business. BCA also continues to develop virtual accounts which are a cash management feature to facilitate the reconciliation of payment transactions, which up to now have been used by \pm 210 companies from various business sectors.

Virtual account developed since 2010 and always developed until 2015 to be more flexible with additional features services and product features and make the account an easier to use (user friendly). The use of Flazz Card (contactless cash card) to complete the cash payment transactions has shown a rapid increase in line with the number of merchants and service points since it was first launched in 2007. Transactions are dominated by large-scale merchants on certain lines of business that have low value transactions but with very high frequency such as parking facilities, retail outlets, gas stations, Trans Jakarta, highway entrance, and other micro outlets such as food and beverage outlets spread throughout Indonesia.

\subsubsection{Commercial Banking and SMEs}


Commercial and SME business segment plays an important role in supporting national economic growth. Taking advantage of its solid position in transactional banking, BCA has the ability to provide credit to qualified customers in the commercial and SME segments. In the commercial banking segment, BCA as a partner provides working capital and medium-scale credit facilities for medium-sized businesses primarily engaged in trade, manufacturing and service industries with loans ranging from Indonesia Rupiah (IDR) 1 to 100 billion. Supported by a commercial business center (SKB), BCA can provide better services and ease of access through experienced relationship officers who offer banking solutions tailored to the needs of commercial customers. Currently, SBK operates in Jakarta, Semarang, Surabaya and Bandung and plans to expand beyond Java Island by the end of 2016. During this year, commercial loans increased by $40.5 \%$ driven by an increase in investment credit and working capital credit respectively $50.0 \%$ and $34.2 \%$ respectively. The quality of commercial credit improved as reflected in the ratio of non-performing loans down from $2.3 \%$ in 2014 to $1.6 \%$ in 2015 .

In the SME segment, BCA provides loan facilities of up to 10 billion. Most SME customers consist of savings account holders and savings accounts that have small family businesses, traders or factories, retail store owners and restaurants. Loan disbursement is made by utilizing BCA's network spread across strategic cities in Indonesia, and is supported by an online and centralized assessment system of credit risk.

Efforts to boost business growth are through intensive marketing in major cities by optimizing the branch network of BCA and continuing to develop various financing solutions using a value chain financing system that leverages the relationship between BCA's corporate and commercial customers. Currently, BCA has a credit system for suppliers, distributors and dealers. In addition, BCA also continues to strengthen its infrastructure, simplify the process and improve the skills and capabilities of account officers in establishing good relationships with customers.

\subsubsection{Corporate Banking}

The growth of corporate banking in 2016 is supported by positive developments from plantation and agricultural sectors, consumer finance and trade. BCA's corporate banking successfully confronts these challenges by continuing to build strong business relationships with existing customers and identifying and striving to attract reputable corporate clients from emerging industries.

The loan portfolio for the commodities sector, including plantations, grew in line with rising demand and global commodity prices, while consumer and trade finance sector grew in line with rising domestic consumption. Corporate lending activities for certain segments, particularly the telecommunications sector, have declined due to the ability of these blue chip companies to obtain financing from alternative sources other than bank lending. BCA continues to be active in providing syndicated loans either as lead arranger, coordinator or participant in infrastructure development financing.

\subsubsection{Cooperation of BCA}


BCA has been cooperating with various companies, both private companies and state companies, including PLN, SOEs, institutional partners, stock exchanges and stock exchanges. BCA has been working with state-owned oil and gas subscribers such as gas stations, oil distributors and LPG agents to develop host-to-host applications for the business. BCA expanded its cooperation with the State gas company in terms of bill payment customers through ATM. Furthermore, BCA cooperates with several corporate clients in promoting the use of Flazz Card (contactless cash card) for the payment of train tickets, tolls, Trans Jakarta, parking, and so on. In addition, BCA enhances cooperation with equity and futures market participants by providing facilities that accelerate the transaction settlement process.

BCA's ability to provide high quality services and secure systems supports PLN in expanding its business and services. BCA's electronic payment transaction services and extensive network provide convenience to customers and create efficiency for PLN in handling PLN subscription bill payments. BCA maintains trust and loyalty by providing more services than promised, and is always quick to take a step forward to meet the needs of corporate banking customers. Moreover, strong banking image and great financing capability, BCA plays an important role in financing PLN projects. BCA helps PLN to realize the construction of power plants in providing adequate infrastructure to mobilize the national economy. One of BCA's participation is as coordinating arranger in syndicated loan for PT. PLN in fast track program in 2010 amounting to (IDR) 267 billion from total syndicated facility worth (IDR) 1,068 billion. The total syndicated loan that was completed by BCA in 2010 was (IDR) 11.6 trillion, of which BCA's portion reached (IDR) 1.6 trillion.

\subsubsection{Products and Services}

BCA seeks continuously to expand its range of products, services and delivery channels. BCA also strives to ensure that every product and service offered is a superior product and service among its customers due to its high quality and professionalism in serving its customers.

BCA also recognizes that customers' needs are constantly changing so that continuous improvement is required with the addition of new features that enhance customer convenience. Some of the facilities offered by BCA currently include ATM, click-BCA, individual internet banking, Hallo BCA, m-BCA, mobile banking and so forth.

For the business community, especially for SME players, BCA offers a variety of products and services tailored to meet their needs, including click-BCA for business and BCA Bizz. BCA also offers various types of credit products to meet customer needs, such as mortgage loans (BCA) BCA, motor vehicle loans (KKB) BCA and credit cooperatives.

\subsection{Implementation and Evaluation of Knowledge Management BCA}

BCA implements a knowledge management system (KMS) as an innovation for BCA culture that is also integrated with innovation center. In KMS, BCA emphasizes three aspects of application targets: systems, people and technology. 


\section{Macrothink}

There are two main reasons why BCA applies KMS, namely:

1. To avoid the existence of valuable tacit knowledge brought out by BCA employees who have retired from BCA.

2. To avoid repetition of processes that have been done before.

\subsubsection{Barriers to the Application of Knowledge Management at BCA}

The main obstacle faced by BCA is the culture of BCA itself, where changes triggered by the implementation of KMS cannot be directly accepted by all BCA employees, because there are some employees who tend to store the knowledge it has.

To overcome these obstacles, BCA provides several media that can be used for knowledge sharing. For example, BCA provides a knowledge sharing forum to capture tacit knowledge from its employees, and BCA also provides a KM portal as a knowledge repository that stores explicit knowledge.

\subsubsection{The Benefits of Knowledge Management for BCA}

Knowledge management is perceived to support BCA's decision-making process, whereby problems encountered by BCA will be clearly noted so that it can be reused to take decisions if the same problem recurs. Knowledge management also supports the continuous creation of BCA's competitive advantage.

\subsubsection{BCA's Main Knowledge Management}

- Standardize employee recruitment to ensure BCA employs good quality employees and reflects company value.

- Knowledge of BCA's financial management strategies such as by selling a portion of BCA's shares and making a number of investments that bring benefits to BCA.

- Knowledge about the products and services that every employee should have.

- Knowledge of strategies to expand the market over time continuously.

- Culture to always create and live social responsibility by providing education funding, funding for disaster-affected people, creating a bank-conscious society etc. 


\subsubsection{Knowledge Management System MAKE in BCA body}

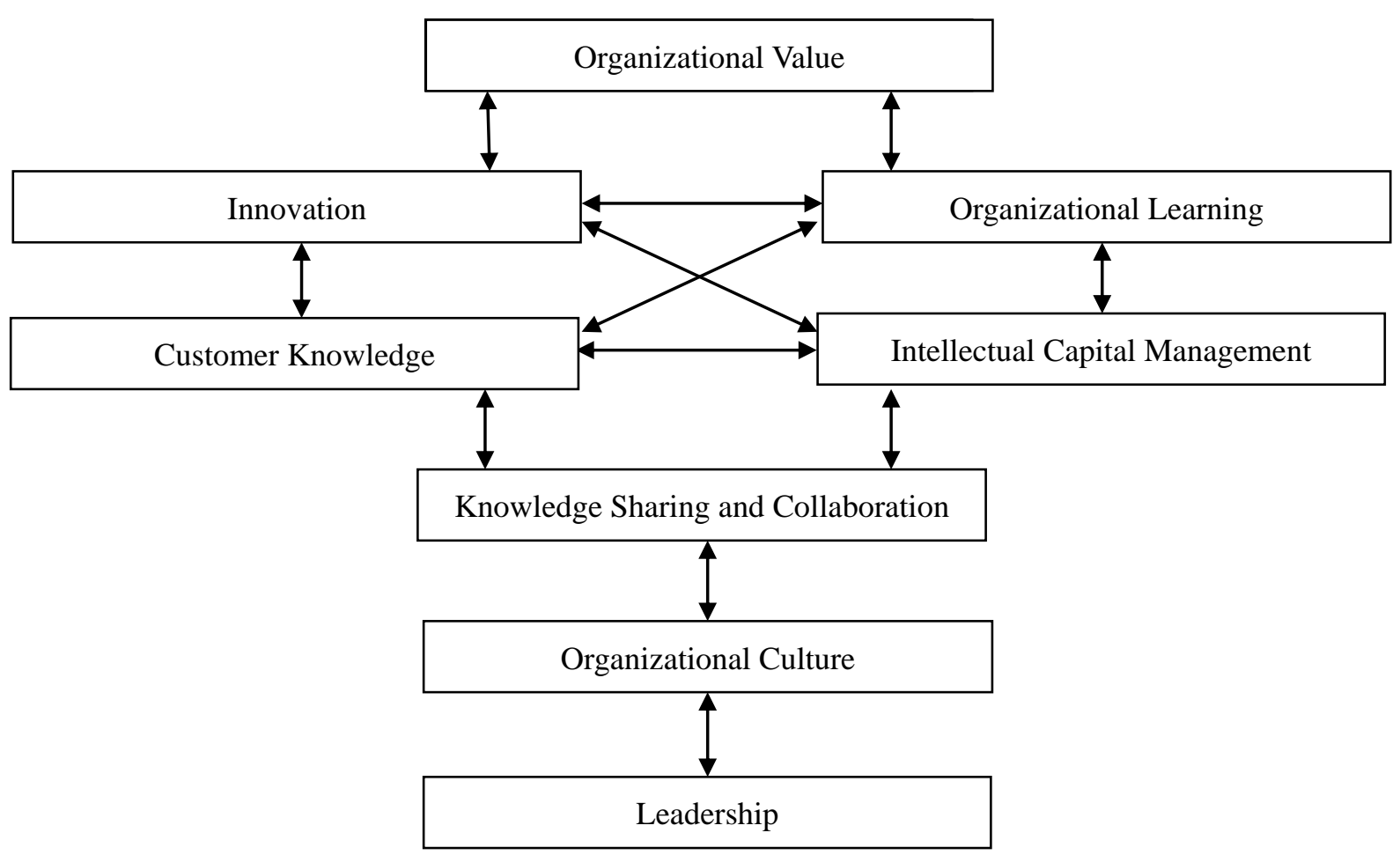

Figure 3. Most Admired Knowledge Enterprise

- Organization Value

Corporate value is the values in the company that can motivate employees to achieve company goals. Corporate value is formulated by top management and designed to achieve the overall corporate objectives. When we discuss Corporate Value, it is indirectly related to organizational culture (organization culture). Corporate values are closely related to company goals, therefore employees need to understand the goals of the company. The impact of entrenched corporate values in an organization's environment will motivate employees to maximize their work.

Corporate value of Bank BCA are:

1. Focus on the Customer

2. Integrity

3. Teamwork

4. Strive to achieve the best

- Innovation

The role of innovation in boosting business performance covers all the important aspects that can add value to the competitiveness of the company, covering aspects of processes, products, markets, management and so on. Therefore, innovation must be run throughout the company in Indonesia, if we do not want competed by competitors in the industry basket that 
continuously encourage innovation in all lines.

BCA uses technology to enhance the ability to innovate in products and services offered to customers primarily for electronic channel products. Focus BCA to innovate and develop electronic channel services in line with BCA's mission to provide ease of transaction in BCA one of them through electronic channel service. Innovation itself departs from an idea to create. BCA made its electronic channel breakthroughs by looking at the needs of its customers.

Some innovations of electronic channel products conducted by BCA are:

1 Machine top up Flazz which gives ease in doing top up and checking Flazz Card balance.

2 ATM print books that provide facilities for customers to print their savings through ATM machines without having to go through a teller that is only available for hours of bank operations.

3 Internet banking and Click-BCA that provide convenience for customers, both individual customers and business "customers" in conducting transactions online anywhere and anytime. Transactions that can be done include checking balances and history, checking foreign exchange rates, transfers and payments.

4 Mobile banking and M-banking that provides convenience for customers in transactions via smartphone anywhere and anytime. Transactions that can be done include checking balances and history, checking foreign exchange rates, transfers and payments.

5 Key banking that provides security facilities in conducting transactions online by providing token numbers.

6 BCA Flazz Cards that make it easy for customers to make transactions via electronic money. This will speed up transactions and minimize errors in the calculation of payment transactions.

7 BCA Bizz that provides facilities for entrepreneurial customers to perform banking transactions such as internet banking services on click-BCA. Where customers can make cash deposits after their stores are closed and services to take / deliver cash. Currently, a number of BCA Bizz has been inaugurated in trade and business centers in several big cities in Indonesia such as Jakarta, Bandung, Semarang and Surabaya.

8 ATM cash deposit that provides facility for customers to make cash deposit to customer's account or other customer's account without having to pass through teller.

BCA electronic channel facility is the most widely used electronic channel of Indonesian society. This facility provides added value and ease in conducting various banking transactions easily and safely, can be done anywhere and anytime. One of the achievements of BCA for its innovations is the "Innovation Award" award for electronic channels in 2005, 2010 and 2012. E-banking technologies also allow BCA to expand its channel selection options.

- Organizational Learning

BCA develops training and development programs with due regard to organizational development needs. BCA has also developed tools and techniques to manage its 


\section{Macrothink Institute ${ }^{\mathrm{TM}}$}

intellectual capital with the BCA intranet, the BCA learning management system both as a knowledge repository and as an online learning system. BCA also requires each intellectual capital to be part of organizational learning in accordance with the values adopted "trying to achieve the best of the intellectual capital that exists in each of BCA's employees". In addition, BCA has always been active in dealing with trainings for its employees throughout Indonesia, both short-term (seminar) and long-term (training).

- Customers Knowledge

BCA provides facilities to gain knowledge of customers and stakeholders to create value and intellectual capital of the organization. Expected by increasing knowledge about customers, BCA can continue to develop and improve its services in accordance with existing market needs and developments, for example by adding new features that enhance customers' convenience. The various facilities include:

1. Hallo BCA: 24-hour call center to assist customers in providing information and handling customer complaints.

2. Website: a website that provides facilities for business customers according to their own needs through the internet network, so that customers can access the necessary data such as banking products, transaction value of buying and selling of foreign currency and so on. In the BCA website, customers can also provide feedback via the contact me (e-mail) feature.

3. Meanwhile, for those who always travel, BCA provides mobile banking services through M-BCA channels, top up with short message service, BCA by phone and BCA hallo.

4. BCA's education programs in the media, including BCA and welcome to BCA, bring banking experts to share their experiences in using BCA's product / banking services.

5. Publications in various magazines and tabloids that explore about the products / services offered by BCA.

6. Social networks like Facebook \& twitter: This social networking is used as one of BCA's CRM system, where BCA provides information on products, facilities and promotional programs to customers. In addition, the customers can provide comments, suggestions or questions directly to the BCA.

7. "Go to the bank" program: a program launched since early 2008 that aims to educate students about the introduction of products and banking services to school students in various cities in Indonesia.

- Intellectual Capital Management

For BCA, human resources is the main asset and capital for the company's success in facing the increasingly competitive banking industry competition. BCA is committed to optimally developing employees 'capabilities and competencies in order to optimally develop employees' capabilities and competencies in order to produce high quality and professional human resources through performance-based work culture programs and actively provide opportunities in career development. 
BCA established the BCA learning center to provide a range of internal training and development programs that are shown to hone skills and cultivation and foster the work ethic needed to support group performance and maintain a high standard of service quality.

This year, the training and development activities of the BCA learning center are focused on programs related to credit, risk management, and knowledge management. During the year, the BCA learning center has organized 2,126 training classes which participated by 64,500 participants from various BCA branches in Indonesia.

Some of the programs undertaken to train and develop the capability and compensation of BCA employees include:

1. BCA management development program (MDP): is a program to increase employee motivation and skill both in technology field and branch expansion to become skilled and professional.

2. BCA development program (BDP): the transformation program of BCA's development management program (MDP), where the program is presented to graduates of S1 and S2 who have high motivation, creative and dynamic to become professionals with integrity in banking.

3. BCA apprenticeship: a program aimed at helping high school graduates to S! To become an experienced individual and ready to enter the workforce. Within the program, candidates will gain knowledge and experience as a banking workforce.

4. Accounting Education Program (PPA): is one form of corporate social function. This program is aimed at high school graduates to develop accounting knowledge and skills in the field of accounting with the aim of preparing professionals in the field of accounting and finance. This non-degree education program also does not charge and has been held for \pm 30 years.

5. Short briefing program: is one of the programs aimed at employees whose purpose is to provide the latest information and knowledge about the banking world, so that employees are expected to know the current state of banking matters.

These programs are shown to produce professional personnel who are specialized in the needs of the work unit. In addition, BCA also organizes mass training programs to expand learning opportunities for all workers in all work units, such as e-learning and video-based training (VBT).

In addition, BCA also provides training programs and the development of its employees externally by sending employees to training institutions both at home and abroad. In addition to developing employee competencies and competencies, BCA also emphasizes employee career development as well as providing opportunities for employees who have contributed to growing and moving forward with BCA. The development of this career will be based on the principles of transparency, equity of opportunity, meritocracy and respect for the performance of its employees.

The BCA compensation system is designed to reflect and reward appropriately for 


\section{Ml Macrothink}

International Journal of Human Resource Studies

ISSN 2162-3058

2017, Vol. 7, No. 4

employee achievement and hard work. Some of the compensations that employees receive are: monthly salaries, holiday allowances, year-end allowances, and annual bonuses.

The benefits that are intended for BCA employees such as:

1. Health, BCA cooperates with clinics and doctors to provide health services for its employees spread in various regions in Indonesia.

2. Loan facility for home and car ownership for employees with interest rate is very attractive.

3. Special treatment in banking services at BCA, among others: special rate, free of charge account, free of charge annual credit card fee, and free of charge transaction.

4. Assistance of education costs for employees who want to continue their studies to the degree and master level.

5. Opportunities for training and learning.

6. Recreation with work units.

BCA uses service oriented architecture (SOA) to avoid redundancy of data and improve decision support so executives can make real time decisions. By using SOA, the process in BCA will also be simpler. BCA also uses a data warehouse that will support customer relationship management (CRM) systems, internet banking and mobile banking.

BCA also has two mainframes in the country. Since each transaction is mirrored on both mainframes, each location can operate independently to handle the overall operating expenses of the bank. BCA also has a mainframe that serves as a disaster recovery center in Singapore, which is prepared to ensure basic operational viability in the event of a disaster in Jakarta.

- Knowledge Sharing and Collaboration

BCA encourages the development of knowledge management, especially in knowledge sharing and collaboration among employees, by forming informal discussion teams to share knowledge, experience and skills with each other across BCA branches in Indonesia.

BCA also supports the formation of various hobby community and employee activities of BCA, among others: Asia lens for photography community, Asia bike for bicycle sports lovers, Asia fishing for employees who have a hobby of fishing and various other communities.

- Organization Culture

The culture of BCA is holistic, historical and determined. The BCA culture also emphasizes the potential development of BCA employees, whereby BCA establishes training programs and each employee is given equal freedom and opportunity to expose his potential, and rewards every outstanding employee. BCA's culture also emphasizes innovation based on human touch so that BCA's innovation products are always closely guarded by BCA employees who are always ready to serve its customers. 


\section{Macrothink}

International Journal of Human Resource Studies

ISSN 2162-3058

2017, Vol. 7, No. 4

The BCA culture emphasizes high social awareness, where business passion is wrapped with a sense of humanity. In various humanitarian tasks, BCA became one of the pioneers. As one of the commitment of social responsibility in running BCA business always apply business ethics and social ethics, and actively participate in community service. Under the auspices of BCA's service program.

The work culture of BCA is based on the performance of its employees. BCA also performs employee recruitment based on top performers.

- Leadership

BCA's senior management provides financial and non-financial support to enhance its knowledge sharing and performance management initiatives among BCA workers. Financial and non-financial support provided include:

1. BCA provides recognition to employees who play a role in knowledge management by rewarding the best instructors and smart rewards for teller, CSO, duty officer, instructor, branch and head office categories by providing opportunities for comparative studies to other companies, both at Both inside and outside the country. In addition to the pocket money and other allowances, as well as scholarships at the end of trading.

2. BCA also strives to create a conducive working environment and a pleasant working environment for employees by facilitating annual recreation for employees to link employee relations and as a means of relaxation for employees. BCA principles that the balance between career life and family life is a very important factor in supporting employee productivity.

3. BCA conducts a mapping of all employees to identify potential employees and competencies aimed at developing a useful development plan to improve the productivity of each employee. One of them is BCA implementing a management panel to identify "top performers" and prepare career development plans for each employee through a series of special training and assignments.

4. Employee career development will be based on the principles of transparency, equity opportunities, meritocracy and rewards towards employee performance.

- BCA Governance

In the face of increasingly complex banking operations, banks are required to uphold the principles of good corporate governance to ensure the sustainability of enterprises, where the implementation of good corporate governance is the main thing in supporting the bank's efforts to always be at the forefront in managing the risks faced. The Board of Commissioners operates an active oversight system through various reports and conducts regular meetings of members of the board of directors as well as the internal audit divisions and committees under the board of commissioners, who have done a good job in providing inputs and recommendations that effectively support the duties and responsibilities of the board of commissioners.

The Committee to meet the highest standards in the implementation of corporate 
governance became one of the key elements underlying BCA's resilience in facing various challenges during the critical period in previous years.

BCA has developed various measures to ensure good corporate governance throughout the organization. One of the efforts to strengthen corporate governance, in 2010 BCA formulated a five year business strategy from 2011 to 2015 in improving the reporting and monitoring system of the board of commissioners. This new reporting and monitoring system is an online dashboard media that can provide information on bank performance and is useful for monitoring and decision making processes of the board of commissioners. BCA also uses the services of other leading consultants to develop an information governance system by implementing capability maturity model integration (CMMI) on a number of projects. CMMI will integrate previously separate organizational functions. The CMII also sets objectives and priorities for improvement, provides guidance for achieving quality processes and provides point of reference for assessing ongoing processes.

\section{Conclusions and Suggestions}

Knowledge management is the strongest according to the author is the innovation where BCA always emphasizes the innovation of both products and facilities that are always developed from time to time. Learning organization BCA is good enough where every branch of BCA in Indonesia is required to make small group to share knowledge on knowledge and skill in each branch. BCA always create programs that support the transfer of information and knowledge such as seminars, training and so forth.

The authors suggest that BCA is recommended to formalize a team or group of discussions at each branch of BCA that links between territorial units in Indonesia to sustain a variety of experiences and knowledge in service and can help each other if there is a similar problem / project. This can be supported by having a system knowledge management system and learning organization that has been built by BCA.

\section{References}

Budihardjo, A. (2016). Knowledge Management. Efektif Berinovasi Meraih Sukses, Prasetya Mulya Publishing, Jakarta

Davidson, C., \& Voss, P. (2003). Knowledge Management: An Introduction to creating competitive advantage from intellectual capital. New Delhi: Vision Books.

Dunamis, T. P. (2013). Successful implementation of KM in Indonesia. Jakarta: Dunamis Intra Sarana.

Girard, J. P., Girard, J. L. (2015). Defining knowledge management: Toward an applied compendium. Online Journal of Applied Knowledge Management, 3(1), 1-20.

Hayes, M., \& Walsham, G. (2003). Knowledge sharing and ICTs: A relational perspective. In Easterby-Smith, M.; Lyles, M.A. The Blackwell Handbook of Organizational Learning and Knowledge Management. Malden, MA: Blackwell. pp. 54-77. 


\section{Macrothink}

International Journal of Human Resource Studies

ISSN 2162-3058 2017, Vol. 7, No. 4

Sanchez, R. (1996). Strategic Learning and Knowledge Management. Chichester: Wiley.

Setiarso, B. (2005). Knowledge Sharing in Organizations: models and mechanism. Special Library Conference. May 15-17, 2005. p 14, Kuala Lumpur.

Tunas, B. (2010). Memahami dan Memecahkan Masalah Dengan Pendekatan Sistem. Jakarta: Nimas Multima.

Source from Internet:

- http://www.bca.co.id (February 11, 2016).

- http://www.klikbca.com (February 11, 2016).

- http://www.mdpbca.com (December 15, 2016).

- http://www.knowledgebusiness.com (Mei 13, 2017).

- http://www.portalhr.com (June 8, 2017).

\section{Copyright Disclaimer}

Copyright for this article is retained by the author(s), with first publication rights granted to the journal.

This is an open-access article distributed under the terms and conditions of the Creative Commons Attribution license (http://creativecommons.org/licenses/by/4.0/). 